\title{
Splicing mutations in human genetic disorders: examples, detection, and confirmation
}

\author{
Abramowicz Anna ${ }^{1} \cdot$ Gos Monika ${ }^{1}$ (D) \\ Received: 18 February 2018 /Revised: 8 April 2018 / Accepted: 10 April 2018 / Published online: 21 April 2018 \\ (C) The Author(s) 2018
}

\begin{abstract}
Precise pre-mRNA splicing, essential for appropriate protein translation, depends on the presence of consensus "cis" sequences that define exon-intron boundaries and regulatory sequences recognized by splicing machinery. Point mutations at these consensus sequences can cause improper exon and intron recognition and may result in the formation of an aberrant transcript of the mutated gene. The splicing mutation may occur in both introns and exons and disrupt existing splice sites or splicing regulatory sequences (intronic and exonic splicing silencers and enhancers), create new ones, or activate the cryptic ones. Usually such mutations result in errors during the splicing process and may lead to improper intron removal and thus cause alterations of the open reading frame. Recent research has underlined the abundance and importance of splicing mutations in the etiology of inherited diseases. The application of modern techniques allowed to identify synonymous and nonsynonymous variants as well as deep intronic mutations that affected pre-mRNA splicing. The bioinformatic algorithms can be applied as a tool to assess the possible effect of the identified changes. However, it should be underlined that the results of such tests are only predictive, and the exact effect of the specific mutation should be verified in functional studies. This article summarizes the current knowledge about the "splicing mutations" and methods that help to identify such changes in clinical diagnosis.
\end{abstract}

Keywords Splicing mutation $\cdot$ Spliceosome $\cdot$ Pre-mRNA splicing $\cdot$ Splicing enhancers and silencers

\section{Introduction}

The mature mRNA contains only coding sequences - the intronic ones are removed from the transcript during the splicing process (Rahman et al. 2015). This process is held in nucleus and is dependent from the presence and interaction between the so-called cis and trans elements. The cis elements are the DNA sequences that define exons, introns, and other regulatory sequences necessary for proper splicing. They are termed consensus splice site sequences and include donor (5') and acceptor ( $3^{\prime}$ ) splice sites, branch point and polypyrimidine tract sequences, and auxiliary cis elements including splicing silencers and enhancers (Fig. 1).

Communicated by: Michal Witt

Gos Monika

monika.gos@imid.med.pl

1 Department of Medical Genetics, Institute of Mother and Child, Kasprzaka 17a, 01-211 Warsaw, Poland
In brief, the splicing process is catalyzed by the spliceosome, a protein-RNA complex containing five small nuclear ribonucleoproteins (snRNPs, U1, U2, U4-U6) and over 300 different proteins. The presence of small nuclear RNAs (snRNAs) in snRNPs allows to form complementary RNA-RNA complexes and thus identify the specific sequences of the splicing sites by the spliceosome (Fig. 2, Faustino and Cooper 2003).

In most of cases (98.7\%), the exon/intron boundary sequences contain GT and AG motifs at the $5^{\prime}$ and $3^{\prime}$ ends of the intron, respectively. Noncanonical GC-AG and AT-AC sequences at the splice sites occur in 0.56 and $0.09 \%$ of the splice site pairs. The noncanonical GC-AG splice site, like the GT-AG splice pair, is processed by major spliceosome complex. The AT-AC splicing motifs, that are present in U-12 type introns, are recognized by functionally relevant U12dependent spliceosome called minor spliceosome (Parada et al. 2014). This complex is similar to the major spliceosome with the exception of several snRNPs. The U1, U2, U4, and U6 are replaced with U11, U12, U4atac, and U6atac, respectively. The U11/U12 proteins bind to their target sequences as a preformed di-snRNP complex (Turunen et al. 2013). 


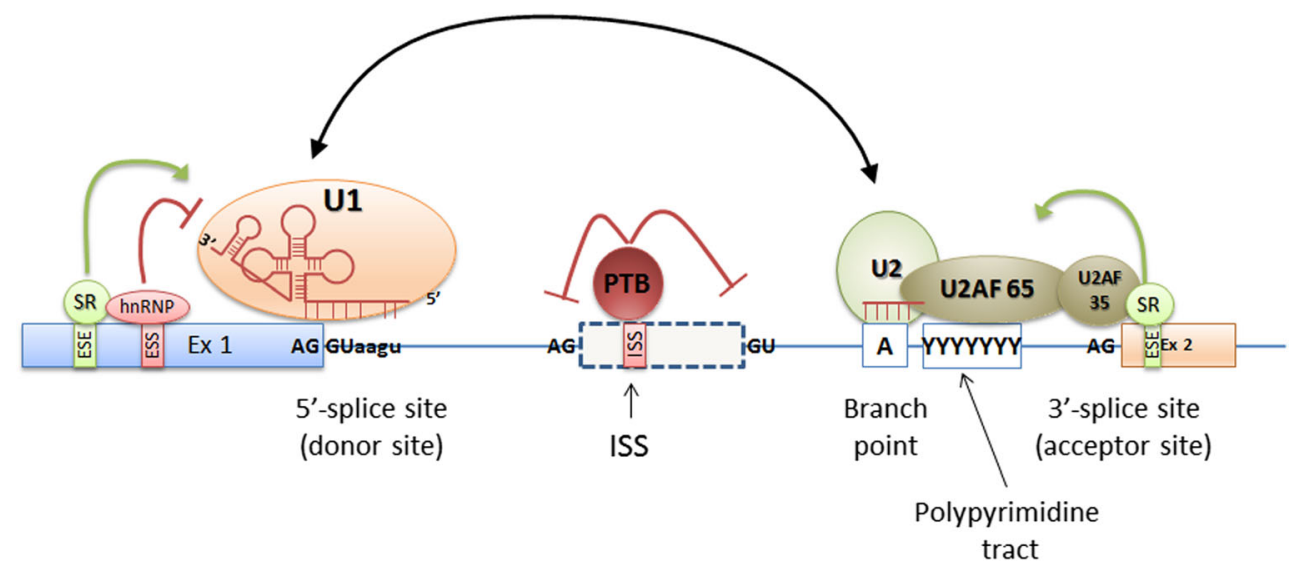

Fig. 1 The schematic localization of the cis and trans splicing elements. The cis elements are the DNA sequences that include donor $\left(5^{\prime}\right)$ and acceptor $\left(3^{\prime}\right)$ splice sites, branch point and polypyrimidine tract sequences, and splicing silencers and enhancers. Donor and acceptor sites are evolutionary conserved and are usually defined by GT and AG nucleotides at the $5^{\prime}$ and $3^{\prime}$ ends of the intron, respectively. The branch site and the polypyrimidine tract sequences are highly degenerated and together with donor and acceptor sites are recognized by the elements of the splicing complex called spliceosome. Spliceosome proteins together with splicing repressors and activators recognize cis splicing elements and are called trans-acting elements
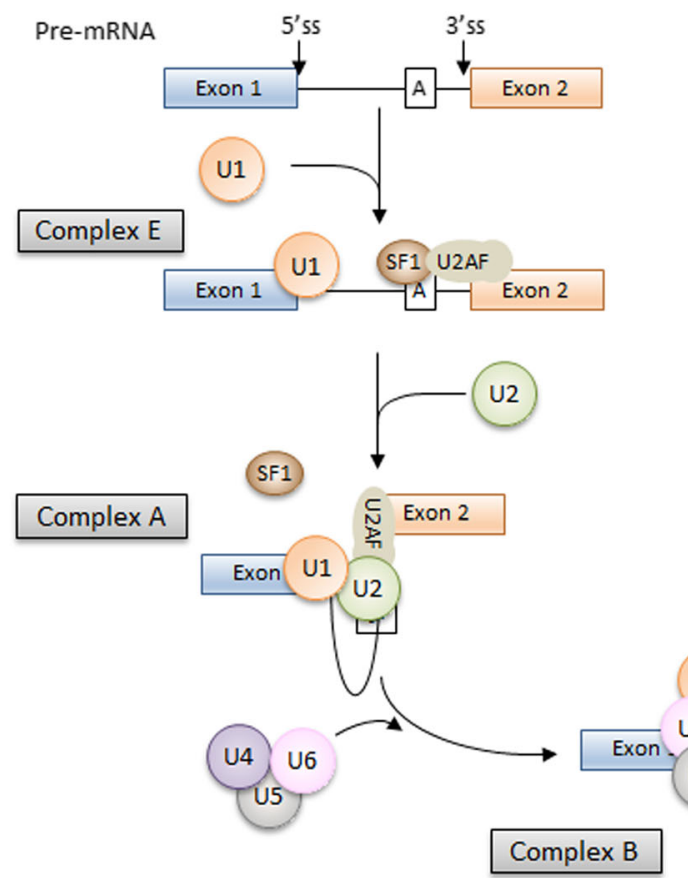

Fig. 2 The scheme of the splicing process. The splicing process is performed in two steps. The first step is the recognition of the splicing sites at intron/exon junctions, and the second one is the intron removal and exon ends joining. During the splicing process, four complexes between the pre-mRNA and spliceosome are formed. The first one is the early complex (E). The U1 snRNP recognizes and binds to the complementary AG-GU sequence at the donor splice site ( $5^{\prime}$ end of the intron). In the same time, the SF1 protein binds to the branch point. The $\mathrm{SF} 1$ is recognized and bound by the U2AF65 protein that also binds to the polypyrimidine sequence located between the branch point and $3^{\prime}$ end of the intron. Then, the SF1 is displaced from the branch point by the U2
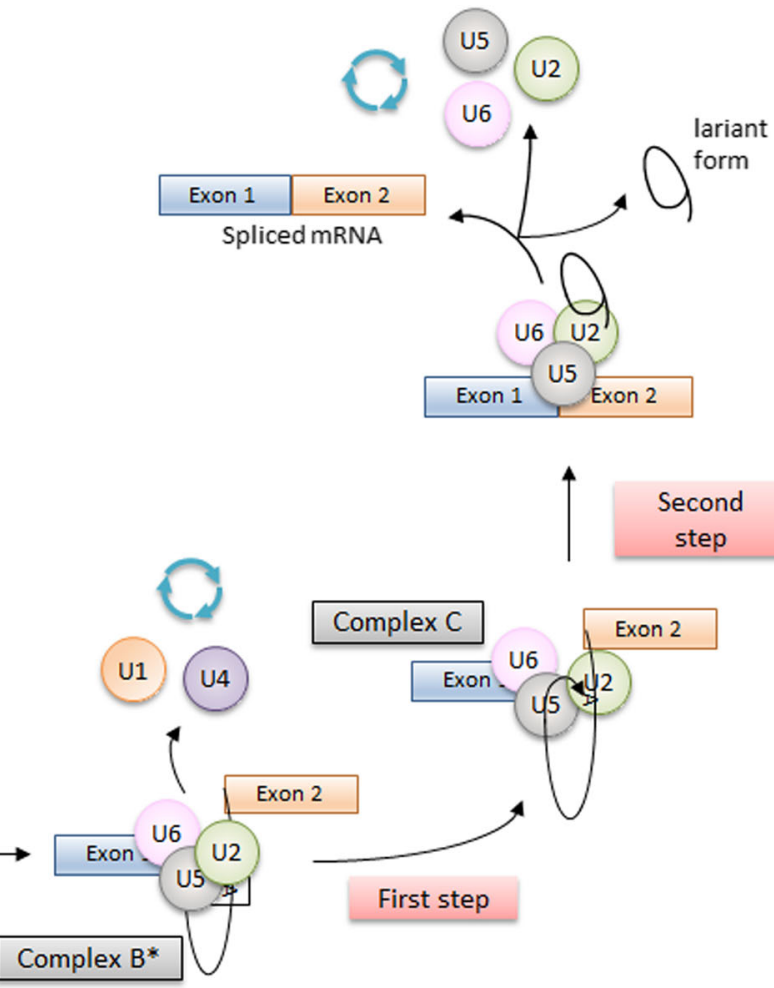

snRNP, and the ATP-dependent (A) complex is formed. The interaction between the branch point and the U2snRNP protein is stabilized by specific RNA helicases (Prp5 and Sub2), and this is a signal for the recruitment of U4/5/6 tri-snRNP and formation of the B complex (precatalytic spliceosome). Further action of additional RNA helicases leads to change of spliceosome conformation that leads to the release of $\mathrm{U} 1$ and U4 snRNPs, the interaction between U6 with U2 snRNP, and the formation of a pre-mRNA loop and the C complex. In this complex, two transesterification reactions take place, intron is removed, and ends of exon are joined (Fredericks et al. 2015; Tazi et al. 2009) 
Any errors during the splicing process may lead to improper intron removal and thus cause alterations of the open reading frame. Therefore, the spliceosome complex has to correctly recognize and cut out the intronic sequences from the premRNA molecule. The proper identification of the splice site is demanding as the consensus sequences are very short and there are many other sequences similar to the consensus motifs of the canonical splice sites. These sequences are known as cryptic, noncanonical, or pseudo splice site sequences. Sometimes, a pseudo splice site matches the consensus sequences better than the natural one, but because of the lack of $c i s$-acting regulatory elements, necessary for the proper exon identification, it is not used in the splicing process (Cartegni et al. 2002). The cis-regulatory elements include exonic and intronic splicing enhancers (ESE and ISE, respectively) and exonic and intronic splicing silencers (ESS and ISS, respectively) (Glisovic et al. 2008). These elements are recognized by specific splicing repressors and activators (trans-acting elements) that help to properly carry out the splicing process.

Splicing enhancers are conserved nucleotide sequences, specifically recognized by the serine and arginine-rich proteins (SR proteins). These proteins bind to the specific intronic/exonic splicing enhancers via RNA recognition motifs and interact with other splicing factors such as snRNP proteins. This interaction is mediated by the C-terminal RS domain of the SR proteins. The SR proteins establish an RNA/RNA interaction at the $5^{\prime}$ splice site and the branch point, assist the formation of an early spliceosomal complex $\mathrm{E}$, and seem to promote the inclusion of exons they are bound with (Caceres and Kornblihtt 2002; Lee and Rio 2015).

Also, negative regulators are involved in the regulation of the splicing process. These proteins, mainly heterogeneous nuclear ribonucleoproteins ( $\mathrm{hnRNP}$ ), bind to exonic and intronic splicing silencers (Wagner and Garcia-Blanco 2001). The hnRNP protein family includes different proteins with molecular weight between 34 and $120 \mathrm{kDa}$, called alphabetically from hnRNP A to hnRNP U (Han et al. 2010). The hnRNP proteins differ with RNA-binding domain (RBD) that is responsible for the interaction specificity (Geuens et al. 2016). Their regulatory action may involve the "looping-out" mechanism - the hnRNP proteins bind to both ends of the exon, and because of their interaction, the exon is "looped out" and becomes blocked to the spliceosome complex. Another proposed mechanism suggests that hnRNPs coat the exon and act as an antagonist of splicing enhancers thus preventing their binding (Caceres and Kornblihtt 2002; Zhang et al. 2008a, b; Kolovos et al. 2012).

To summarize, the splicing process is a complex event that is important for proper protein synthesis. Any alterations of this process might lead to the decrease of the level of the specific messenger RNA and thus deprivation of the protein level that can result in aberrant cellular metabolism and/or function (Chabot and Shkreta 2016). The aberrant splicing of pre-mRNA due to the presence of point mutations, e.g., nucleotide substitutions, that alter the consensus splicing regulatory sequences in a specific gene, may lead to the specific hereditary monogenic disorders. This article summarizes the current knowledge about the "splicing mutations" and methods that help to identify such changes in clinical diagnosis.

\section{Cis-element splicing mutations}

In general, the term splicing mutations usually refers to the point mutation at the cis consensus sequences that effects in improper exon and intron recognition in messenger RNA and results in the generation of an aberrant transcript of the mutated gene. The splicing mutation may occur in both introns and exons and disrupt existing splice sites, create new ones, or activate the cryptic ones. They also can influence splicing enhancers and silencers binding or alter the secondary structure of messenger RNA and therefore prevent the binding of the spliceosome elements. Usually such mutations result in exon/exon fragment skipping during the pre-mRNA splicing. If the resulting deletion is an in-frame one, the shorter protein will be synthetized. When the deletion results in the shift of the open reading frame, a premature stop codon (PTC) can be introduced and shorter protein can be produced. However, the presence of the PTC in the transcript usually leads to faster mRNA degradation during a protective process called nonsense mediated decay (NMD). The degradation of the defective messenger RNA prevents aberrant protein synthesis and has the same effect as gene deletion or nonsense mutation (Sterne-Weiler and Sanford 2014). According to Wimmer et al. (2007), splicing mutations can be briefly divided into five categories that are further briefly discussed (Fig. 3).

\section{Mutations in the canonical acceptor and donor sites (type I and IV mutations)}

In general, mutations in the canonical acceptor and donor sites affect strongly conserved sequences that define exon-intron boundaries. The $5^{\prime}$ splice site (CAG/GUAAGU sequence) and $3^{\prime}$ splice site (NYAG/G sequence) are recognized by the elements of the spliceosome. Therefore, any variants in these canonical sequences might alter interaction between premRNA and proteins involved in the intron removal. The most classical mutations affect +1 and +2 residues at the $5^{\prime}$ donor splice site and -1 and -2 residues at the $3^{\prime}$ acceptor splice site. The meta-analysis of splicing mutations (478 mutations in 38 selected genes) indicated that the donor splice site mutations were more prevalent than the acceptor splice site variants (ratio 1.5:1) (Krawczak et al. 2007). Similar results were obtained if a single gene was taken into consideration. Pros et al. (2008) had found that the splicing mutations in the NF1 

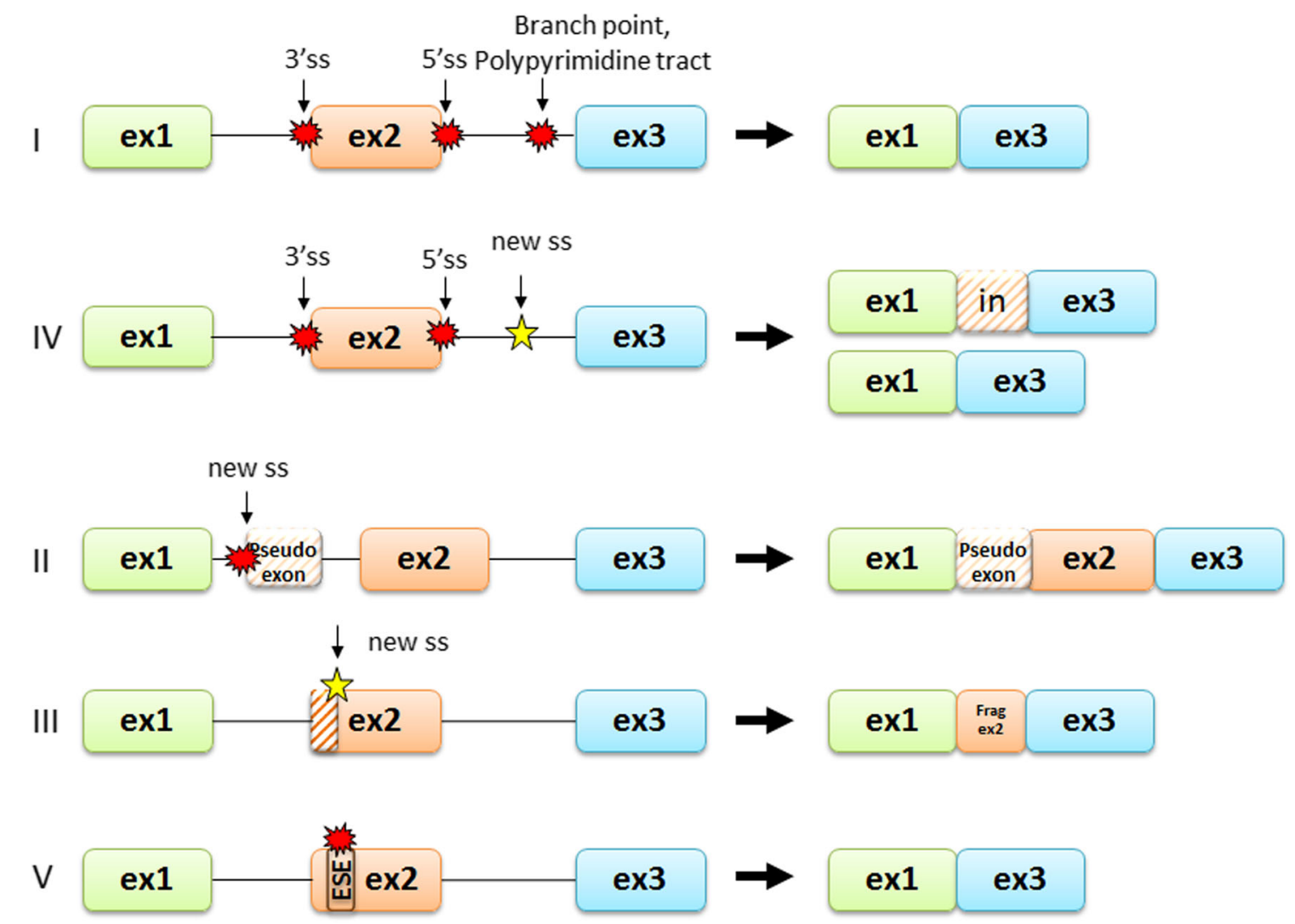

Fig. 3 The types of splicing mutations. According to Wimmer et al. (2007), splicing mutations can be briefly divided into five categories: (1) splicing mutations within the canonical splice sites leading to whole exon skipping, (2) deep intronic variants creating new splice sites resulting in the inclusion of cryptic exons, (3) exonic single nucleotide variants creating new splice sites that result in the loss of an exon

gene more frequently affected $5^{\prime}$ splice site $(65 \%)$ than the $3^{\prime}$ one (35\%). According to HGMD® Professional database (release 2017.3), this difference is lower and equals to $56 \%$ and $44 \%$ for $5^{\prime}$ and $3^{\prime}$ splice site, respectively.

Mutations at the canonical splice sequences usually lead to single exon skipping (type I mutation, see Table 1). However, if the splice site is weak and the presence of mutation uncovers the cryptic splice site in a neighboring exon or intron, this alternative site can be used in the splicing process (type IV mutation). This can lead to the inclusion of the intron fragment or the removal of an exon fragment if the cryptic splice site is present in intron or exon, respectively. In such situation, several distinct transcripts can be generated like in the case of the c. $1525-1 \mathrm{G}>\mathrm{A}$ variant in intron 9 of the CFTR gene. Detailed analysis revealed the presence of three different mRNA isoforms that utilized distinct alternative splice sites located within intron 10 and exon 10 at positions c.1610-1611 and c.1678-1679 and were lacking whole exon 10 or its fragments, respectively (Ramalho et al. 2003).

The effect of mutation at the canonical splice site might also depend on the strength of the splicing site, localization of cryptic splice sites, density of ESE and ESS, or secondary fragment, (4) variants in the canonical splice sites resulting in the usage of the cryptic exonic or intronic splice site that leads to the inclusion of an intron fragment or exon fragment skipping, and (5) mutations within the exon, usually leading to ESE disruption, resulting in the entire exon skipping

structures formed by the pre-mRNA. The functional study of selected splicing mutations in the $D M D$ gene revealed that the same substitution at the same position from the exon can lead to different effect. The NM_004006.2: c.3277+1G $>$ A mutation in intron 25 leads to the removal of exon 25 from the transcript, while the NM_004006.2: c.6439+1G $>$ A mutation in intron 45 activates the cryptic exonic splicing site resulting in the inclusion of exon 45 shorter by $32 \mathrm{bp}$ at the $3^{\prime}$ end. The experimental studies with minigene assays have confirmed this observation and shown that in the case of the c.6439+ $1 \mathrm{G}>\mathrm{A}$ mutation, three distinct splicing isoforms that use different alternative cryptic sites were observed. The authors suggested that the splicing mutation in introns with strong (highly similar to the consensus motifs, e.g., with high complementarity to the $5^{\prime}$ end of the U1 snRNA) splicing motifs, like the donor site of the intron 45 of the $D M D$ gene, stimulates the use of cryptic splice sites in exons and introns. The splicing complex specifically recognizes strong splice site, and if the canonical splicing site is mutated, there is a higher probability of the activation of the cryptic splice site. In the case of weak splice sites, the probability of whole exon skipping is higher than the use of alternative splicing motifs. The 


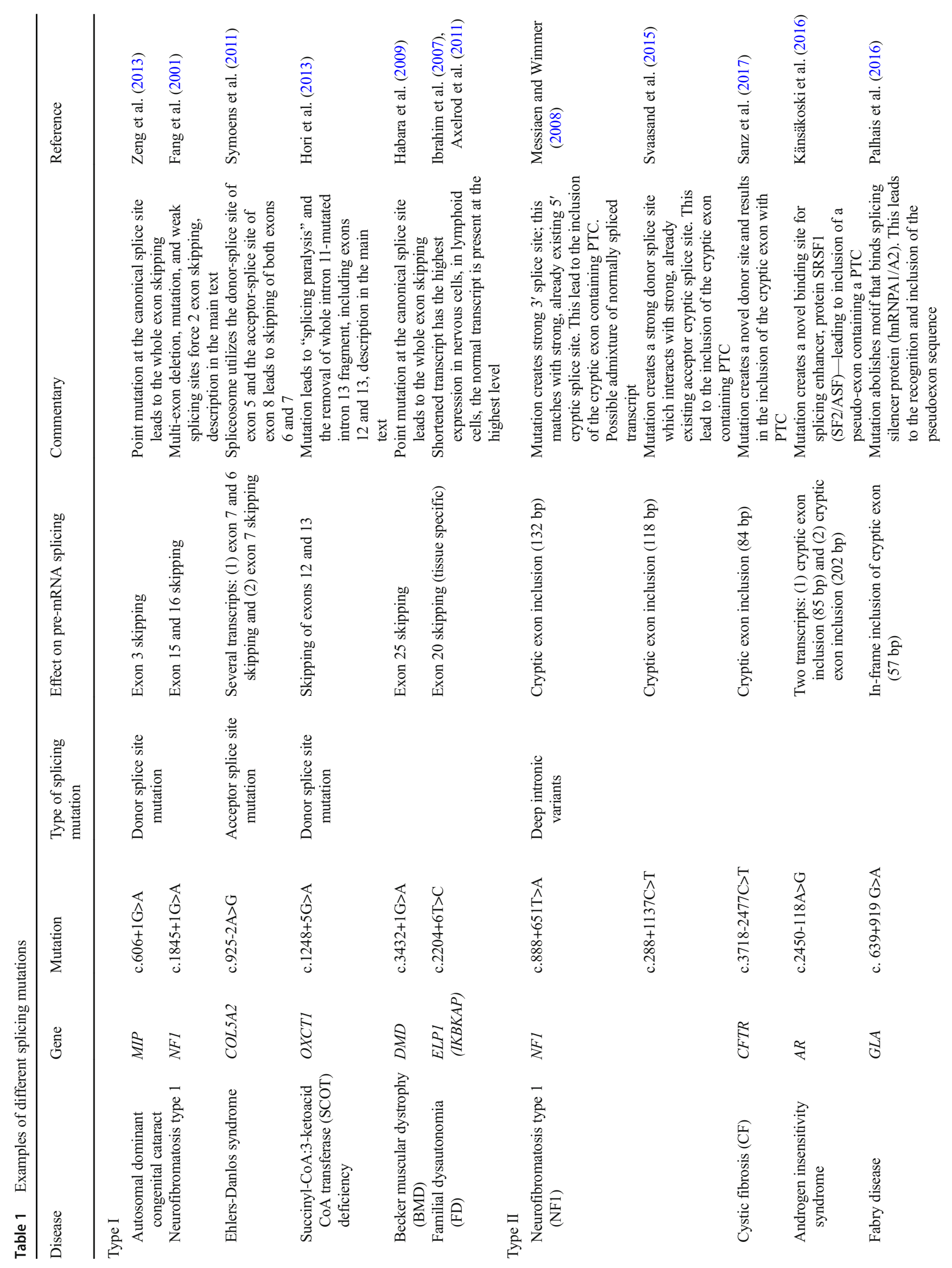




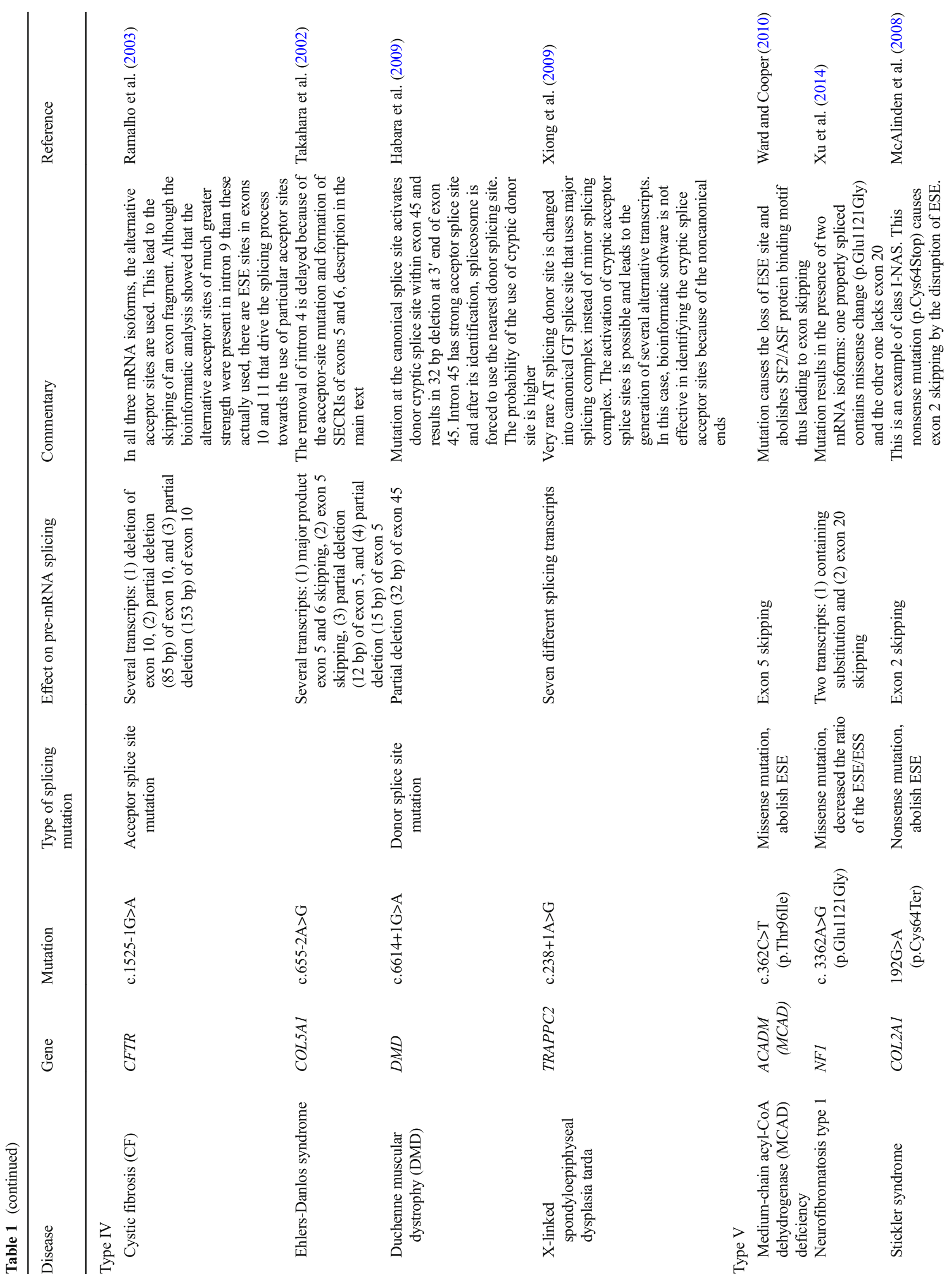




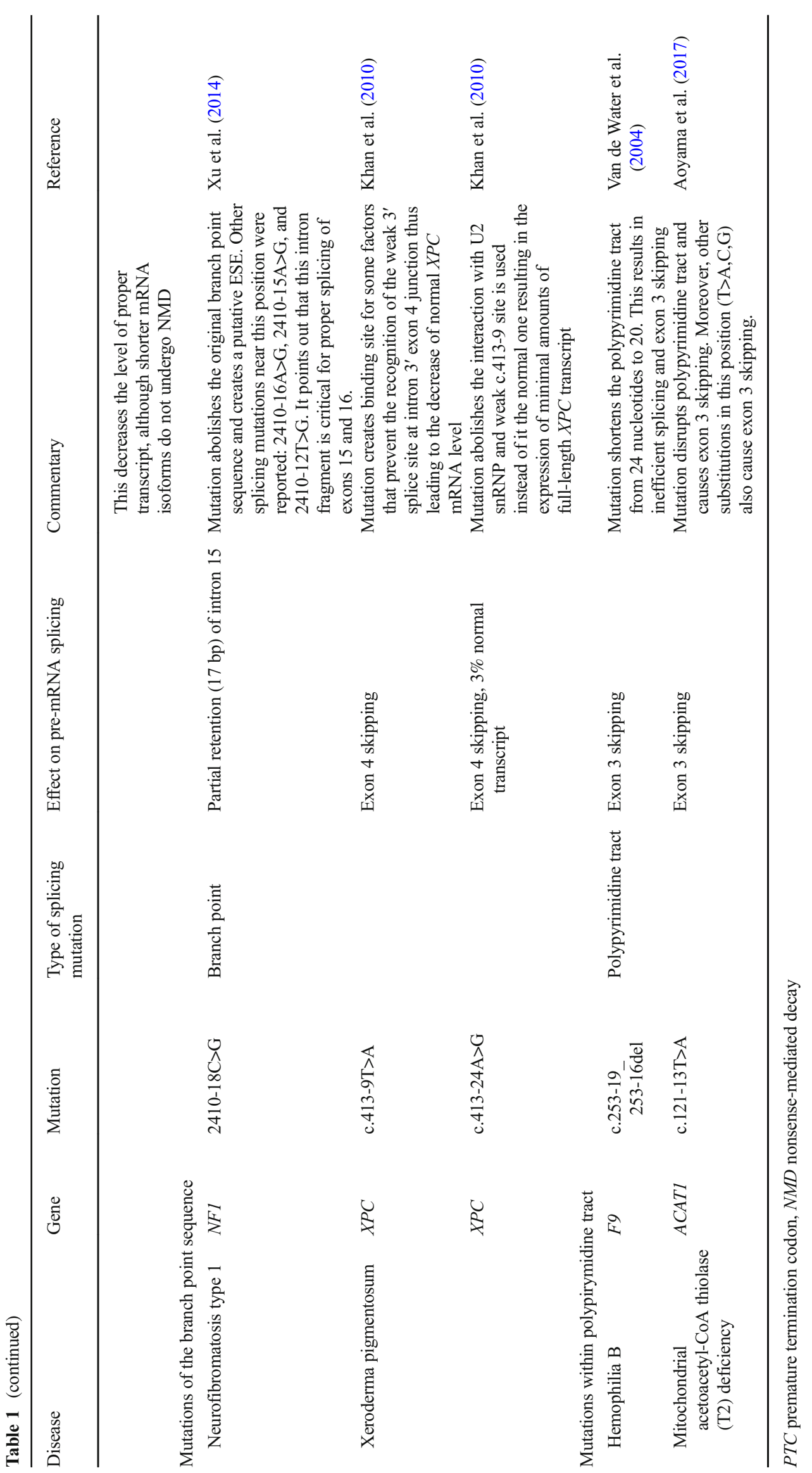


authors also checked other 14 mutations affecting +1 position of the $D M D$ gene and found that this observation was true for all variants that were localized in exons longer than $170 \mathrm{bp}$ (Habara et al. 2009).

In certain circumstances, several exons might be deleted like in the case of the c. $1845+1 \mathrm{G}>\mathrm{A}$ variant in the $N F 1$ gene that leads not only to exon 16 but also to the upstream exon 15 removal. During the splicing process of the mutated premRNA, the donor site in the intron 14 and acceptor site in intron 16 are utilized. The proposed model for double exon skipping emphasizes the role of strong consensus splice sites. The exon 15 is surrounded by weak splicing sites, and strong splicing sites of the exon 16 are needed for proper intron 15 and 16 removal. If the strong donor site of the intron 16 is weakened due to the presence of the $c .1845+1 \mathrm{G}>\mathrm{A}$ mutation, the stronger splicing sites at the intron 14 are recognized by the splicing machinery and exon 15 is removed from the transcript (Fang et al. 2001).

The deletion of several exons and generation of distinct mRNA isoforms due to the presence of a splicing mutation might be also related to the order of intron removal. This was analyzed in detail in the case of the c.655-2A $>$ G mutation in the COL5A1 gene that mutations were found in Ehlers-Danlos syndrome (EDS) patients. In the cells taken from the patient with this mutation, several transcripts were found. The major one was lacking exons 5 and 6 , the other one was lacking only exon 5, while in two other transcripts 12 and 15 , nucleotides of exon 5 were missing due to the use of the cryptic splicing sites. It was suggested that the major transcript is created because of the delayed removal of the intron 4 due to the presence of acceptor site mutation. As the removal of the intron 5 is not affected, a large multiexon structure called "spliced exon clusters in RNA intermediates" (SECRI) consisting of exons 5 and 6 is formed. Subsequent splicing events can lead to the removal of both exons 5 and 6 and the formation of the major transcript. It can occur, however, that only intron 6 is removed from the SECRI and the transcript that contains spliced exons 5, 6, and 7 can be a substrate for the splicing the used cryptic acceptor sites located in the exon 5. In the case of the transcript lacking only exon 5, it was suggested that the first intron being removed is the intron 6 thus preventing the removal of both exons 5 and 6 (Takahara et al. 2002).

The third mechanism that was proposed to explain the skipping of several exons due to the splicing mutation was the "splicing paralysis" model. It was described in detail for the c. $1248+5 \mathrm{G}>\mathrm{A}$ mutation in $O X C T 1$ gene that was found in patient with succinyl-CoA:3-ketoacid CoA transferase deficiency (Hori et al. 2013). This mutation leads to the skipping of exons 12 and 13 from the transcript and first studies aimed to identify appropriate SECRI intermediates, but without any success. Further functional analysis had shown that introns in the normal transcript were spliced in the following order: intron 13, 12, and 11. The presence of mutation affecting donor site of the intron 13 caused the delay in this intron removal thus also affecting the time of intron 12 and 11 splicing. Authors suggested that this caused so-called splicing paralysis that could be solved by the removal of whole intron 11mutated intron 13 fragment, including exons 12 and 13 (Hori et al. 2013).

The effect of a specific splicing mutation may also depend on the tissue type in which the primary transcript is expressed and thus the availability of the specific factors. A good example is the c. $2204+6 \mathrm{~T}>\mathrm{C}$ mutation in the IKBKAP gene, that is found in homozygous state in about $99 \%$ of patients with familial dysautonomia inherited in autosomal recessive manner (Cuajungco et al. 2003; Slaugenhaupt et al. 2001). The bioinformatic analysis with Human Splicing Finder (HSF) did not predict that the c.2204+6T $>C$ variant affects splicing. The functional studies had shown, however, that this substitution caused skipping of the exon 20. Functional analysis of the IKBKAP RNA level in distinct tissue types revealed that the wild-type transcript was present at different levels in all examined samples. Its level was the highest in lymphocytederived cell lines, while the transcript lacking exon 20 had the highest expression in nervous cells. This can explain why the nervous system deficits are the most prominent in familial dysautonomia patients (Ibrahim et al. 2007; Axelrod et al. 2011).

\section{Deep intronic variants as a cause of cryptic exon inclusion (type II mutations)}

Another category of splicing mutations includes deep intronic mutations - usually substitutions localized within large introns that result in the inclusion of an intron fragment- - socalled cryptic exon or pseudoexon, into the mature transcript. Functionally, such variants create novel acceptor or donor sites that are recognized by the splicing complex and are used in combination with the existing intronic cryptic splice sites. It is also possible that deep intronic mutations result in the creation of novel regulatory elements (e.g., splicing enhancers) and the recognition of the specific intronic sequences as an exonic ones (detailed review in Vaz-Drago et al. 2017).

One of the most common and well-known deep intronic change is a c.3718-2477C $>\mathrm{T}$ (legacy name: c. $3849+10 \mathrm{~kb}$ $\mathrm{C}>\mathrm{T}$ ) variant being one of the most frequent mutations in CFTR gene responsible for cystic fibrosis in Polish population (Sobczyńska-Tomaszewska et al. 2013). This mutation is located within the intron 19 and creates a novel donor site that results in the inclusion of an 84-bp cryptic exon into the mature mRNA. This cryptic exon contains an in-frame STOP codon, and thus, the translated protein is shorter and nonfunctional (Sanz et al. 2017). The CF patients with c.3718$2477 \mathrm{C}>\mathrm{T}$ mutation often have a relatively mild phenotype with a variable disease expression. It was found that the 
severity of the disease is inversely correlated with the level of correctly spliced transcripts that suggest that the splicing regulation might be an important modifier of the CF clinical course in the presence of intronic mutations. Functional studies had shown that the overexpression of the HTRA2- $\beta 1$, SC35 splicing factors in the presence of the c.3718$2477 \mathrm{C}>\mathrm{T}$ mutation promotes proper CFTR pre-mRNA splicing and restored the function of the chloride channel (NissimRafinia et al. 2004).

Deep intronic mutations are not common, but their effect on transcript splicing and further protein synthesis is significant. The analysis for the presence of such mutations should be considered when the identification of potentially pathogenic variants in the coding regions and exon/intron boundaries was not effective, and the patient phenotype is specific for a mutation is a specific gene. The techniques that can be helpful in the identification of deep intronic mutations that include RNA/cDNA sequencing and genome or targeted whole gene next-generation sequencing. However, the mutations identified on genomic level should be confirmed with functional RNA testing.

\section{Exonic mutations affecting splicing (type III and V) mutations}

Apart from the intronic mutations affecting canonical splicing sites or activating cryptic exons, also the changes in the exonic sequences may affect the pattern of pre-mRNA splicing. Such exonic mutations might have double effect. First, they can introduce a new $5^{\prime}$ or $3^{\prime}$ splice site or activate the cryptic one that would be stronger than the original one, thus leading to changes in pre-mRNA processing and the loss of an exon fragment (so-called type III splicing mutation). Second, the presence of exonic changes that cause the disruption of exonic splicing enhancers may also lead to the entire exon skipping (so-called type $\mathrm{V}$ splicing mutation) (Wimmer et al. 2007).

The application of the RNA/cDNA sequencing in the diagnosis of genetic diseases helps to identify type III and V splicing mutations. In genes that are analyzed with this approach, many different variants were identified and shown to influence proper pre-mRNA processing. According to LOVD mutation database (accessed on 10.10.2017), 26 exonic splicing mutations were identified in the NF1 gene. Eighteen of them $(69 \%)$ affected regulatory splicing sequences, especially ESE motifs, resulting in the specific exon skipping. The other mutations $(8.31 \%)$ created a new cryptic splice site thus leading to the deletion of the exon fragment.

The exonic mutation causing splicing alterations can be easily misclassified as synonymous, missense, or nonsense variant. Usually, the presence of such variants results in the generation of two different transcripts from one mutated allele: one has a proper length and has a modified nucleotide, and the other one is shorter and lack whole exon or its fragment due to the nonspecific activity of the splicing complex (Nissim-Rafinia and Kerem 2002). For example, the presence of c.3362A $>\mathrm{G}$ variant in the $N F 1$ gene results in two mRNA isoforms: one properly spliced contains the substitution that can lead to missense change at the protein level (p.Glu1121Gly), and the other one lacks exon 20. The transcript mosaicism was confirmed with in vitro quantitative studies in two patients harboring this mutation. One of them had higher level of the transcript lacking exon 20, although it did not seem to correlate with the disease severity as both patients presented similar phenotype. It was suggested that the level of different transcript isoforms might be related to the individual genetic variability (Xu et al. 2014).

It is worth to mention in this section the process called nonsense-associated altered splicing (NAS) that was described as a mechanism that should protect transcripts containing premature STOP codons from the nonsense-mediated decay (Cartegni et al. 2002). During this process, the transcripts containing PTC are alternatively spliced and fragments with premature nonsense codon are removed from mature RNA. The exact mechanism of this process has not been described in detail, but it is obvious that in certain circumstances, it is dependent from the frameshift of the reading frame and not from the ESE disruption (so-called class II-NAS). This process was described in the context of the regulation of TCR $\beta$ transcripts (Wang et al. 2002). More common are examples of class I-NAS - altered splicing due to the presence of the nonsense mutation that affects ESE site and results in whole exon skipping (Bühler and Mühlemann 2005). Such variants have been described in the FBN1, BRCA1, or COL2A1 genes (see Table 1).

\section{Mutations affecting branch point and polypyrimidine tract}

As mentioned, the splicing process is also dependent from the presence of specific sequences: branch site and the polypyrimidine tract sequences that bind specific proteins involved in the formation of splicing complexes. The branch point motif, localized between -9 and -400 bp downstream from the acceptor site with the consensus sequence YUNAY in humans, is essential for early spliceosome complex formation. As the sequences of the branch point are highly degenerated, their exact localization is difficult to determine. It seems, however, that mutations localized in the branch point sequence might lead to an exon skipping due to improper binding of the SF1 and U2 snRNP splicing proteins and disruption of the natural acceptor splicing site. Mutations in branch point sequence can also cause intron retention (whole or its fragment) if they create new $3^{\prime}$ splice site (Caminsky et al. 2014).

The polypyrimidine tract with sequence enriched in pyrimidine nucleotides $/(\mathrm{Y})_{12-17} /$ is located between 5 and $40 \mathrm{bp}$ 
from the acceptor splice site, upstream from the branch point sequence. This sequence binds the U2AF65 spliceosome subunit and polypyrimidine tract-binding protein that is involved in alternative splicing regulation. Any mutations in this sequence probably lead to splicing alterations, although the list of such variants is limited (Ward and Cooper 2010).

Point mutations at the branch point and polypyrimidine tract are very rare and hard to identify when the genomic DNA, mainly coding sequences, are analyzed. As the consensus sequences of these motifs are degenerated, it is hard to predict their exact localization and therefore conclude about the possible effect of a specific variant in these regions. Many of mutations affecting branch point or polypyrimidine tract described so far have been identified by the RNA/cDNA sequencing, or their effect was assessed in functional studies with minigene assay (see "Functional analysis of splicing mutation" section). Such analysis should be performed to confirm the splicing effect of an intronic variant identified near the acceptor splice site (Lewandowska 2013).

\section{How to detect and confirm splicing mutation?}

About $9 \%$ of all mutations reported in the Human Gene Mutation Database (HGMD) are splicing mutations (18761/ 208368) (HGMD database, accessed on October 10, 2017), although it is obvious that this number may be underestimated. Most of the reported mutations were identified by genomic DNA sequencing, and it cannot be ruled out that the number of missense or nonsense substitutions is in fact splicing mutations especially when occur within cis-acting elements. Only in several monogenic disorders (e.g., neurofibromatosis type I), the RNA sequencing was implemented into routine molecular diagnosis, mainly due to the problems with RNA stability and availability. Nevertheless, the application of this method allowed to identify synonymous (silent) and nonsynonymous/nonsense mutations as well as deep intronic mutations that affected pre-mRNA splicing. This underlined the fact that the analysis of the DNA sequences (exome or gene) should also include the identification of possible splicing mutations. As the functional testing is challenging, the in silico algorithms were developed to test for possible splicing alterations (Table 2).

\section{In silico analysis of potential slicing mutation}

These tools were developed for research purposes, although in certain circumstances can be implemented into routine diagnostics. Algorithms proposed for splicing analysis differ between each other with the database containing information about the consensus sequences, the statistical model used for the analysis, or training methods that are used in machine learning approaches. Most of the tools focus on the analysis of the consensus splicing sites and require the sequence input at least including positions $-3_{-}+6$ or $-20_{-}+3$ in the case of $5^{\prime}$ donor and $3^{\prime}$ acceptor sites, respectively. These tools are based on position weight matrix model (Analyzer Splice Tool, SpliceView), probabilistic maximum dependence decomposition model (GENSCAN, GeneSplicer), machine learning techniques (NetGene2, NNSplice - artificial neural networks, SplicePort-support vector machine, SplicePredictor - no web interface, Bayesian model), or maximum entropy distribution model (MaxEntScan). There are also tools developed to detect how distant mutation may influence splicing (Spliceman) or to predict exon skipping, cryptic site activation, or generation of aberrant transcripts from primary sequence (CRYP-SKIP logistic regression model). To predict whether a single nucleotide variant can affect branch site sequence or polypirymidine tract, specific algorithms were developed to identify these sites (e.g., Branch Site Analyzer, SVM-BPfinder) or to predict variant pathogenicity (e.g., IntSplice — support only vcf files; Jian et al. 2014; Ohno et al. 2018).

Also, the effect of a specific variant on the possible ESE or ESS alterations should be examined in the case of exonic mutations. There are several algorithms that can be used to assess these changes like ESE Finder, based on functional SELEX method or RESCUE-ESE Web Server, RESCUEbased MODEL HEXplorer score, and ESRsearch, all three based on relative enhancer and silencer classification by unanimous enrichment approach using frequencies of hexameric sequences. Some models are based on the results of the functional analyses of random sequences for enhancer or silencer properties with minigene assays (FAS-ESS) or the direct interaction between selected splicing factors and their RNA target motifs (SpliceAid2). Only SPANR tool uses splicing code modeling-based approach and was trained on data from different human tissues. The EX-SKIP and HOT-SKIP tools integrate several approaches to analyze potential ESE/ESS sequences (Grodecká et al. 2017). Other bioinformatic programs, such as mFold or pFold, can be used to predict whether a given mutation may affect mRNA secondary structure (Caminsky et al. 2014).

For the maximum comfort of the user, some programs that use different algorithms were developed and made available via the website. The most known are Human Splicing Finder (HSF) and SROOGLE, that predict the presence of cissplicing elements in the uploaded sequence or generate prediction for a particular variant in a specific gene. Another SNV prediction online tool is MutPredSplice that can analyze single variant or a set of variants uploaded as a vcf file. Multiple algorithms were also implemented in a commercially available software like Alamut Visual Software (Interactive Biosoftware) or MutationForecaster (includes a tool previously known as ASSEDA; CytoGnomix ${ }^{\circledR}$ Inc). 
Table 2 Prediction algorithms for the analysis of splicing effect

Prediction of splice sites

\begin{tabular}{|c|c|c|}
\hline NetGene2 & http://www.cbs.dtu.dk/services/NetGene2/ & Hebsgaard et al. (1996), Brunak et al. (1991) \\
\hline $\begin{array}{l}\text { Splice Site Prediction by } \\
\text { Neural Network }\end{array}$ & www.fruitfly.org/seq_tools/splice.html & Reese et al. (1997) \\
\hline SplicePredictor & http://brendelgroup.org/bioinformatics2go/SplicePredictor.php & Brendel et al. (2004) \\
\hline Splice port & http://spliceport.cbcb.umd.edu/ & Dogan et al. (2007) \\
\hline SpliceView & http://bioinfo.itb.cnr.it/oriel/splice-view.html & $\begin{array}{l}\text { Shapiro and Senapathy (1987), } \\
\text { Rogozin and Milanesi (1997) }\end{array}$ \\
\hline Analyzer Splice Tool & http://ibis.tau.ac.il/ssat/SpliceSiteFrame.htm & Carmel et al. (2004) \\
\hline GENSCAN & http://genes.mit.edu/GENSCAN.html & Burge and Karlin (1997) \\
\hline GeneSplicer & http://www.cbcb.umd.edu/software/GeneSplicer/gene_spl.shtml & Pertea et al. (2001) \\
\hline MaxEntScan & http://genes.mit.edu/burgelab/maxent/Xmaxentscan_scoreseq.html & Yeo and Burge (2004) \\
\hline Spliceman & http://fairbrother.biomed.brown.edu/spliceman/ & Lim et al. (2011), Lim and Fairbrother (2012) \\
\hline CRYP-SKIP & http://cryp-skip.img.cas.cz/ & Divina et al. (2009) \\
\hline SROOGLE & http://sroogle.tau.ac.il/ & Schwartz et al. (2009) \\
\hline Human Splicing Finder & www.umd.be/HSF/ & Desmet et al. (2009) \\
\hline MutPredSplice & http://www.mutdb.org/mutpredsplice/submit.htm & Mort et al. (2014) \\
\hline Alamut Visual Software & http://www.interactive-biosoftware.com & Interactive Biosoftware \\
\hline MutationForecaster & https://mutationforecaster.com/index.php & CytoGnomix ${ }^{\circledR}$ Inc. \\
\hline \multicolumn{3}{|c|}{ Prediction of branch site and polypyrimidine tract } \\
\hline Branch Site Analyzer & http://ibis.tau.ac.il/ssat/BranchSite.htm & Kol et al. (2005) \\
\hline SVM-BPfinder & http://regulatorygenomics.upf.edu/Software/SVM_BP/ & Corvelo et al. (2010) \\
\hline IntSplice & https://www.med.nagoya-u.ac.jp/neurogenetics/IntSplice/ & Shibata et al. (2016) \\
\hline \multicolumn{3}{|l|}{ Variant annotations } \\
\hline Variant Effect Predictor tool & https://www.ensembl.org/info/docs/tools/vep/index.html & $\begin{array}{l}\text { Ensembl release 91—December 2017@ } \\
\text { EMBL-EBI }\end{array}$ \\
\hline Alamute Batch software & http://www.interactive-biosoftware.com/alamut-batch/ & \\
\hline \multicolumn{3}{|l|}{ Prediction of ESE or ESS } \\
\hline ESEfinder & http://exon.cshl.org/ESE & Cartegni et al. (2003), Smith et al. (2006) \\
\hline RESCUE-ESE programs & http://genes.mit.edu/burgelab/rescue-ese/ & Fairbrother et al. (2002) \\
\hline HEXplorer score & https://www2.hhu.de/rna/html/hexplorer_score.php & Erkelenz et al. (2014) \\
\hline ESRsearch & http://esrsearch.tau.ac.il/ & $\begin{array}{l}\text { Goren et al. (2006), Fairbrother et al. (2002), } \\
\text { Zhang and Chasin (2004) }\end{array}$ \\
\hline FAS-ESS & http://genes.mit.edu/fas-ess/ & Wang et al. (2004) \\
\hline SpliceAid2 & http://193.206.120.249/splicing_tissue.html & Piva et al. (2012) \\
\hline SPANR tool & http://tools.genes.toronto.edu/ & Xiong et al. (2015) \\
\hline EX-SKIP & http://ex-skip.img.cas.cz/ & Raponi et al. (2011) \\
\hline HOT-SKIP & http://hot-skip.img.cas.cz/ & Raponi et al. (2011) \\
\hline \multicolumn{3}{|c|}{ Prediction of mRNA secondary structure } \\
\hline mFold & http://unafold.rna.albany.edu/?q=mfold & Zuker (2003) \\
\hline pFold & http://daimi.au.dk/ compbio/pfold/ & Knudsen and Hein (2003) \\
\hline
\end{tabular}

Also, advanced tools used for variant annotations (e.g., from next generation sequencing) can utilize splicing prediction algorithms. For example, the Variant Effect Predictor tool, that is also available online, includes special plugins that perform splicing analysis with MaxEntScan model and dbscSNV matrix (a part of the dbNSFP database). The commercial software for variant annotation, like Alamut Batch software (Interactive Biosoftware), also includes analysis of splicing mutation. The Alamut Batch uses MaxEntScan, HSF, NNSplice, GeneSplicer, and other tools for splicing analysis (user manual available at http:/www.interactivebiosoftware.com). 


\section{Functional analysis of splicing mutation}

The bioinformatic algorithms are a useful tool in the assessing the possible effect of the identified changes, although it should be underlined that the result of such test is only predictive, and the exact effect of the mutation should be verified in functional studies. An additional test that can be used to confirm that the specific splicing variant has a pathogenic effect is the analysis of a variant segregation with the disease in affected and unaffected family members performed at the DNA level, but still the exact splicing effect should be tested in laboratory (Théry et al. 2011; Fredericks et al. 2015). There are several methods that can be used to analyze the functional effect of a particular variant. The effect of the splicing mutations can be tested on different levels: DNA, RNA, RNA-protein interactions, or protein level itself.

The simplest and the most effective method to determine whether the selected variant affects splicing is to analyze the RNA extracted from a relevant patient tissue or cell line derived from a patient cells. The sequencing of RNA/cDNA after reverse transcription PCR (RT-PCR) allows to verify whether the identified variant influence the mRNA sequence. The main problem with such approach is the possibility of nonsense-mediated decay. In such situation, the effect of the potential splicing mutation can be easily missed out. To overcome this disadvantage, the patient cells can be treated with NMD inhibitors such as puromycin that blocks RNA degradation (Baralle and Baralle 2005). The most common materials used for such functional testing are patient fibroblasts or short-term cultures of blood mononuclear cells (leukocytes).

If the appropriate material for functional RNA sequencing is not available, an alternative possibility is a minigene assay - an in vitro hybrid system that allows for "exon trapping." This system is especially useful to the analysis of genes with low expression level in leukocytes or fibroblasts (Singh and Cooper 2006). In minigene assay, the amplified fragment of the analyzed gene, e.g., specific exon with surrounding intronic sequences with and without mutations, is cloned into a special expression plasmid enabling the analysis the pre-mRNA splicing (Fig. 4). This approach can be used to confirm that the potential splicing variant affects splicing efficiency or causes the activation of the alternative cryptic splicing sites, and to test the role of a cis-acting elements on splicing regulation (Sharma et al. 2014).

These techniques are limited because they do not assess the relative level of transcript isoforms. The most valuable method to resolve this problem is real-time PCR (RT-PCR) or quantitative PCR (qPCR) which enables to measure the quantity of each mutated transcript and compare it to the level of the nonmutated one. This method also allows to test whether the mutated transcript undergo NMD (Xu et al. 2014).

The protein truncation test (PTT) was designed as a screening tool to identify mutations that lead to the formation of PTC and resulting in shorter proteins. The test consists of four steps: (1) generation of a template for protein synthesis by amplification of the DNA fragment or RT-PCR of the mRNA, (2) in vitro template transcription and translation in the presence of labeled methionine or leucine amino acids, (3) electrophoresis (SDS-PAGE) of the synthetized proteins, and (4) visualization and assessment of the protein size. When the splicing, nonsense, or frameshift mutation that results in PTC is present, the shorter than expected protein is synthetized. Using this method, the protein abundance and its size are easy to assess (Hauss and Müller 2007). Nowadays, this method was replaced by Sanger or next-generation sequencing, but it remains an option to test for possible splicing defects resulting in shortened protein.

\section{Summary}

It is clear that mutations affecting splicing pattern may be the cause of genetic disorders, although their frequency might be underestimated. During the genomic DNA analysis, they can be easily overlooked and erroneously classified as synonymous changes or benign amino acid substitutions. However, the analysis of RNA/cDNA clearly shows that such mutations have a significant impact on the pre-mRNA splicing. It was assumed that larger genes with long introns were more prone to splicing defects, but it is now more obvious that also a significant number of mutations in smaller genes also cause abnormal mRNA splicing (Chen and Manley 2009). In addition, the analysis of $N F 1$ and ATM genes showed that many of the identified splicing mutations were located outside the canonical splicing sites and could be easily missed during genomic DNA analysis. There is a growing evidence that misclassification of mutation is a common error and the overall number of splicing defects is probably underestimated (Xiong et al. 2015).

The importance of splicing mutations in the pathogenesis of genetic diseases gave rise to numerous experimental and clinical studies that focus on the development of drugs that can reverse the effect of splicing mutations. The most promising approach is the use of antisense oligonucleotides (AONs; Pros et al. 2009; Bergsma et al. 2018). The AONs are short synthetic DNA or RNA molecules that recognize complementary target pre-mRNA fragments and can modulate its splicing by blocking of binding sites for proteins involved in the regulation of the splicing process (Siva et al. 2014). Synthetic AONs can be used to prevent aberrant splicing or to induce additional exon exclusion to restore the proper reading frame. The first approach is used in the therapy of spinal muscular atrophy (SMA), autosomal recessive disorder in $95 \%$ of cases caused by homozygous deletion of exon 7 of the SMN1 gene (Jedrzejowska et al. 2010). In the 5q13.2 locus, there is a paralogue of the SMN1 gene- the SMN2 gene 
Fig. 4 The principles of minigene assay. In the minigene assay, the amplified fragment of the analyzed gene, e.g., specific exon with surrounding intronic sequences with and without mutations, is cloned into a special expression plasmid enabling the analysis the pre-mRNA splicing (see description in text)

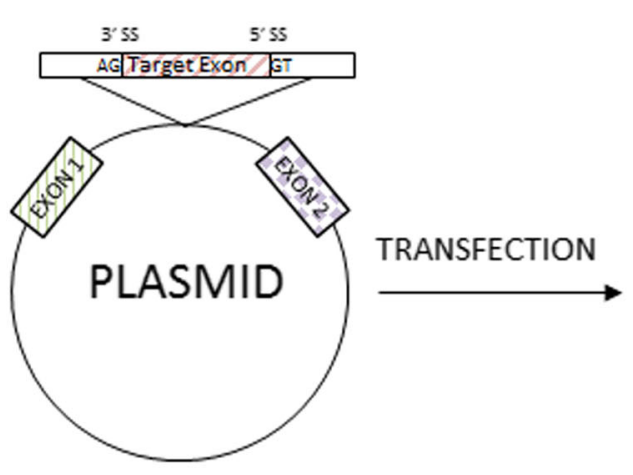

WT

\begin{tabular}{|c|c|c|}
\hline & 3 ss & \\
\hline \begin{tabular}{l|l} 
EXON 1 & GT
\end{tabular} & AGTarget Exon GT & AGEXXN 2 \\
\hline
\end{tabular}

SPLICING

\begin{tabular}{|l|l|l|}
\hline EXON 1 & Target EXON & EXON 2 \\
\hline
\end{tabular}

EXON INCLUSION

MUTANT

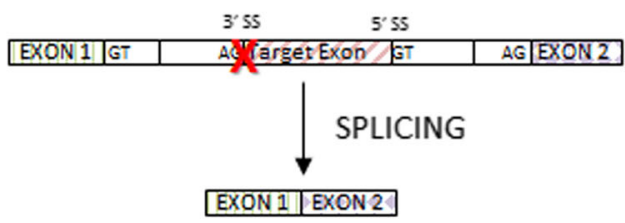

EXON SKIPPING that differs with five nucleotides from the original one. It encodes the identical protein, although the $S M N 2$ transcript processing is ineffective due to the presence of $\mathrm{c} .840 \mathrm{C}>\mathrm{T}$ substitution in the exon 7. Its presence results in exon 7 skipping in about $80 \%$ of $S M N 2$ transcripts, and a truncated, quickly degraded nonfunctional protein is synthetized. Two models have been proposed to explain exon 7 skipping. First assumes that the presence of $\mathrm{c} .830 \mathrm{C}>\mathrm{T}$ substitution causes ESE disruption and inhibits the binding of SF2/ASF splicing activators (Cartegni and Krainer 2002). The second one proposes that the substitution leads to the formation of the exonic splicing silencer that binds hnRNPA1 and represses exon 7 inclusion to the transcript (Kashima et al. 2007; Cartegni et al. 2006). Nevertheless, the Spiranza — an ASO drug that was developed for SMA patients-blocks splicing silencers near the exon 7 of the SMN2 gene thus generating properly spliced (exon 7 included) transcripts that encode functional SMN protein. The clinical testing has shown high efficacy of Spiranza treatment in patients with all types of SMA (Chiriboga 2017).

The approach that induces exon skipping to restore reading frame was developed for Duchenne muscular dystrophy patients with frameshift mutations in the $D M D$ gene. In these patients, it was proved that large in-frame deletions are less deleterious than mutations causing loss of reading frame, and this triggered the idea of the restoration of a reading frame with ASO. First studies focused on the exon 51 skipping, as the deletion of this exon is frequently seen in DMD patients, and the developed drugs (drisapersen and eteplirsen) were successfully used in clinical trials (Veltrop and Aartsma-Rus 2014). The promising results of the ASO-based therapies demonstrate that the treatment of genetic disorders caused by splicing defects is possible and this points out the importance of the identification of such mutations in clinical samples.
Acknowledgments We would like to thank Prof. Jerzy Bal for the critical review of the article and his insightful comments about the manuscript.

Funding The studies on neurofibromatosis type I and other RASopathies are possible thanks to the Institute of Mother and Child Intramural Grants and Polish National Science Centre grant UMO-2013/09/B/NZ2/03164.

\section{Compliance with ethical standards}

Conflict of interest The authors declare that they have no conflict of interest.

Ethical approval This article does not contain any studies with human participants or animals performed by any of the authors.

Open Access This article is distributed under the terms of the Creative Commons Attribution 4.0 International License (http:// creativecommons.org/licenses/by/4.0/), which permits unrestricted use, distribution, and reproduction in any medium, provided you give appropriate credit to the original author(s) and the source, provide a link to the Creative Commons license, and indicate if changes were made.

\section{References}

Aoyama Y, Sasai H, Abdelkreem E, Otsuka H, Nakama M, Kumar S, Fukao T (2017) A novel mutation (c.121-13T >A) in the polypyrimidine tract of the splice acceptor site of intron 2 causes exon 3 skipping in mitochondrial acetoacetyl-CoA thiolase gene. Mol Med Rep 15:3879-3884

Axelrod FB, Liebes L, Gold-von Simson G et al (2011) Kinetin improves IKBKAP mRNA splicing in patients with familial dysautonomia. Pediatr Res 70(5):480-483

Baralle D, Baralle M (2005) Splicing in action: assessing disease causing sequence changes. J Med Genet 42(10):737-748

Bergsma AJ, van der Wal E, Broeders M, van der Ploeg AT, Pim Pijnappel WWM (2018) Alternative splicing in genetic diseases: 
improved diagnosis and novel treatment options. Int Rev Cell Mol Biol 335:85-141

Brendel V, Xing L, Zhu W (2004) Gene structure prediction from consensus spliced alignment of multiple ESTs matching the same genomic locus. Bioinformatics 20:1157-1169

Brunak S, Engelbrech J, Knudsen S (1991) Prediction of human mRNA donor and acceptor sites from the DNA sequence. J Mol Biol 220: $49-65$

Bühler M, Mühlemann O (2005) Alternative splicing induced by nonsense mutations in the immunoglobulin $\mu$ VDJ exon is independent of truncation of the open reading frame. RNA 11(2):139-146

Burge C, Karlin S (1997) Prediction of complete gene structures in human genomic DNA. J Mol Biol 268:78-94

Caceres JF, Kornblihtt AR (2002) Alternative splicing: multiple control mechanisms and involvement in human disease. Trends Genet 18(4):186-193

Caminsky N, Mucaki EJ, Rogan PK (2014) Interpretation of mRNA splicing mutations in genetic disease: review of the literature and guidelines for information-theoretical analysis. F1000Res 3:282

Carmel I, Tal S, Vig I, Ast G (2004) Comparative analysis detects dependencies among the $5^{\prime}$ splice-site positions. RNA 10(5):828-840

Cartegni L, Krainer AR (2002) Disruption of an SF2/ASF-dependent exonic splicing enhancer in SMN2 causes spinal muscular atrophy in the absence of SMN1. Nat Genet 30(4):377-384

Cartegni L, Chew SL, Krainer AR (2002) Listening to silence and understanding nonsense: exonic mutations that affect splicing. Nat Rev Genet 3(4):285-298

Cartegni L, Wang J, Zhu Z, Zhang MQ, Krainer AR (2003) ESEfinder: a web resource to identify exonic splicing enhancers. Nucleic Acid Res 31(13):3568-3571

Cartegni L, Hastings ML, Calarco JA, de Stanchina E, Krainer AR (2006) Determinants of exon 7 splicing in the spinal muscular atrophy genes, SMN1 and SMN2. Am J Hum Genet 78(1):63-77

Chabot B, Shkreta L (2016) Defective control of pre-messenger RNA splicing in human disease. J Cell Biol 212(1):13-27

Chen M, Manley JL (2009) Mechanisms of alternative splicing regulation: insights from molecular and genomics approaches. Nat Rev Mol Cell Biol 10(11):741-754

Chiriboga CA (2017) Nusinersen for the treatment of spinal muscular atrophy. Expert Rev Neurother 17(10):955-962

Corvelo A, Hallegger M, Smith CWJ, Eyras E (2010) Genome-wide association between branch point properties and alternative splicing. Meyer IM, ed. PLoS Comput Biol 6(11):e1001016

Cuajungco MP, Leyne M, Mull J, Gill SP, Lu W, Zagzag D et al (2003) Tissue-specific reduction in splicing efficiency of IKBKAP due to the major mutation associated with familial dysautonomia. Am J Hum Genet 72:749-758

Desmet FO, Hamroun D, Lalande M, Collod-Béroud G, Claustres M, Béroud C (2009) Human Splicing Finder: an online bioinformatics tool to predict splicing signals. Nucleic Acids Res 37(9):e67

Divina P, Kvitkovicova A, Buratti E, Vorechovsky I (2009) Ab initio prediction of mutation-induced cryptic splice-site activation and exon skipping. Eur J Hum Genet 17(6):759-765

Dogan RI, Getoor L, Wilbur WJ, Mount SM (2007) SplicePort-an interactive splice-site analysis tool. Nucleic Acids Res 35(Web Server issue):W285-W291

Erkelenz S, Theiss S, Otte M, Widera M, Peter JO, Schaal H (2014) Genomic HEXploring allows landscaping of novel potential splicing regulatory elements. Nucleic Acids Res 42(16):10681-10697

Fairbrother WG, Yeh RF, Sharp PA, Burge CB (2002) Predictive identification of exonic splicing enhancers in human genes. Science 297(5583):1007-1013

Fang LJ, Simard MJ, Vidaud D, Assouline B, Lemieux B, Vidaud M, Chabot B, Thirion JP (2001) A novel mutation in the neurofibromatosis type 1 (NF1) gene promotes skipping of two exons by preventing exon definition. J Mol Biol 307(5):1261-1270
Faustino NA, Cooper TA (2003) Pre-mRNA splicing and human disease. Genes Dev 17(4):419-437

Fredericks AM, Cygan KJ, Brown BA, Fairbrother WG (2015) RNAbinding proteins: splicing factors and disease. Biomol Ther 5(2): 893-909

Geuens T, Bouhy D, Timmerman V (2016) The hnRNP family: insights into their role in health and disease. Hum Genet 135(8):851-867

Glisovic T, Bachorik JL, Yong J, Dreyfuss G (2008) RNA-binding proteins and post-transcriptional gene regulation. FEBS Lett 582(14): 1977-1986

Goren A, Ram O, Amit M, Keren H, Lev-Maor G, Vig I, Pupko T, Ast G (2006) Comparative analysis identifies exonic splicing regulatory sequences - the complex definition of enhancers and silencers. Mol Cell 22(6):769-781

Grodecká L, Buratti E, Freiberger T (2017) Mutations of pre-mRNA splicing regulatory elements: are predictions moving forward to clinical diagnostics? Int J Mol Sci 18(8):1668

Habara Y, Takeshima Y, Awano H, Okizuka Y, Zhang Z, Saiki K, Yagi M, Matsuo M (2009) In vitro splicing analysis showed that availability of a cryptic splice site is not a determinant for alternative splicing patterns caused by $+1 \mathrm{G}->$ A mutations in introns of the dystrophin gene. J Med Genet 46(8):542-547

Han SP, Tang YH, Smith R (2010) Functional diversity of the hnRNPs: past, present and perspectives. Biochem J 430(3):379-392

Hauss O, Müller O (2007) The protein truncation test in mutation detection and molecular diagnosis. Methods Mol Biol 375:151-64

Hebsgaard SM, Korning PG, Tolstrup N, Engelbrecht J, Rouze P, Brunak S (1996) Splice site prediction in Arabidopsis thaliana DNA by combining local and global sequence information. Nucleic Acids Res 24(17):3439-3452

Hori T, Fukao T, Murase K, Sakaguchi N, Harding CO, Kondo N (2013) Molecular basis of two-exon skipping (exons 12 and 13) by c.1248+ $5 \mathrm{~g}>\mathrm{a}$ in OXCT1 gene: study on intermediates of OXCT1 transcripts in fibroblasts. Hum Mutat 34(3):473-480

Ibrahim EC, Hims MM, Shomron N, Burge CB, Slaugenhaupt SA, Reed R (2007) Weak definition of IKBKAP exon 20 leads to aberrant splicing in familial dysautonomia. Hum Mutat 28:41-53

Jedrzejowska M, Milewski M, Zimowski J, Zagozdzon P, KosteraPruszczyk A, Borkowska J, Sielska D, Jurek M, HausmanowaPetrusewicz I (2010) Incidence of spinal muscular atrophy in Poland - more frequent than predicted? Neuroepidemiology 34(3): $152-157$

Jian X, Boerwinkle E, Liu X (2014) In silico prediction of splice-altering single nucleotide variants in the human genome. Nucleic Acids Res 42(22):13534-13544

Känsäkoski J, Jääskeläinen J, Jääskeläinen T et al (2016) Complete androgen insensitivity syndrome caused by a deep intronic pseudoexon-activating mutation in the androgen receptor gene. Sci Rep 6:32819

Kashima T, Rao N, David CJ, Manley JL (2007) hnRNP A1 functions with specificity in repression of SMN2 exon 7 splicing. Hum Mol Genet 16(24):3149-3159

Khan SG, Yamanegi K, Zheng Z-M et al (2010) XPC branch-point sequence mutations disrupt $\mathrm{U} 2$ snRNP binding resulting in abnormal pre-mRNA splicing in xeroderma pigmentosum patients. Hum Mutat 31(2): 167-175

Knudsen B, Hein J (2003) Pfold: RNA secondary structure prediction using stochastic context-free grammars. Nucleic Acids Res 31(13): 3423-3428

Kol G, Lev-Maor G, Ast G (2005) Human-mouse comparative analysis reveals thatbranch-site plasticity contributes to splicing regulation. Hum Mol Genet 14(11):1559-1568

Kolovos P, Knoch TA, Grosveld FG, Cook PR, Papantonis A (2012) Enhancers and silencers: an integrated and simple model for their function. Epigenetics Chromatin 5(1): 1 
Krawczak M, Thomas NS, Hundrieser B, Mort M, Wittig M, Hampe J, Cooper DN (2007) Single base-pair substitutions in exon-intron junctions of human genes: nature, distribution, and consequences for mRNA splicing. Hum Mutat 28(2):150-158

Lee Y, Rio DC (2015) Mechanisms and regulation of alternative premRNA splicing. Annu Rev Biochem 84:291-323

Lewandowska M (2013) The missing puzzle piece: splicing mutations. Int J Clin Exp Pathol 6(12):2675-2682

Lim KH, Fairbrother WG (2012) Spliceman - a computational web server that predicts sequence variations in pre-mRNA splicing. Bioinformatics 28(7):1031-1032

Lim KH, Ferraris L, Filloux ME, Raphael BJ, Fairbrother WG (2011) Using positional distribution to identify splicing elements and predict pre-mRNA processing defects in human genes. Proc Natl Acad Sci U S A 108(27):11093-11098

McAlinden A, Majava M, Bishop PN, Perveen R, Black GC, Pierpont ME, Ala-Kokko L, Männikkö M (2008) Missense and nonsense mutations in the alternatively-spliced exon 2 of COL2A1 cause the ocular variant of Stickler syndrome. Hum Mutat 29(1):83-90

Messiaen LM, Wimmer K (2008) NF1 mutational spectrum. In: Kaufmann D (ed) Neurofibromatoses, vol 16. Karger, Basel, pp 63-77

Mort M, Sterne-Weiler T, Li B et al (2014) MutPred Splice: machine learning-based prediction of exonic variants that disrupt splicing. Genome Biology 15(1): R19. Nissim-Rafinia M, Aviram M, Randell SH, et al (2004) Restoration of the cystic fibrosis transmembrane conductance regulator function by splicing modulation. EMBO Rep 5(11):1071-1077

Nissim-Rafinia M, Kerem B (2002) Splicing regulation as a potential genetic modifier. Trends Genet 18(3):123-127

Nissim-Rafinia M, Aviram M, Randell SH, Shushi L, Ozeri E, ChibaFalek O, Eidelman O, Pollard HB, Yankaskas JR, Kerem B (2004) Restoration of the cystic fibrosis transmembrane conductance regulator function by splicing modulation. EMBO Rep 5(11):1071-1077

Ohno K, Takeda JI, Masuda A (2018) Rules and tools to predict the splicing effects of exonic and intronic mutations. WIREs RNA 9: e1451. https://doi.org/10.1002/wrna.1451

Palhais B, Dembic M, Sabaratnam R, Nielsen KS, Doktor TK, Bruun GH, Andresen BS (2016) The prevalent deep intronic c. 639+919 G>A GLA mutation causes pseudoexon activation and Fabry disease by abolishing the binding of hnRNPA1 and hnRNP A2/B1 to a splicing silencer. Mol Genet Metab 119(3):258-269

Parada GE, Munita R, Cerda CA, Gysling K (2014) A comprehensive survey of non-canonical splice sites in the human transcriptome. Nucleic Acids Res 42(16): 10564-10578

Pertea M, Lin X, Salzberg SL (2001) GeneSplicer: a new computational method for splice site prediction. Nucleic Acids Res 29(5):11851190

Piva F, Giulietti M, Burini AB, Principato G (2012) SpliceAid 2: a database of human splicing factors expression data and RNA target motifs. Hum Mutat 33(1):81-85

Pros E, Gómez C, Martín T, Fábregas P, Serra E, Lázaro C (2008) Nature and mRNA effect of 282 different NF1 point mutations: focus on splicing alterations. Hum Mutat 29(9):E173-E193

Pros E, Fernández-Rodrígue J, Canet B, Benit L, Sánchez A, Benavides A, Ramos FJ, López-Ariztegui MA, Capellá G, Blanco I, Serra E, Lázaro C (2009) Antisense therapeutics for neurofibromatosis type 1 caused by deep intronic mutations. Hum Mutat 30:454-462

Rahman M, Nasrin F, Masuda A, Kinji O (2015) Decoding abnormal splicing code in human diseases. J Investig Genomics 2(1):00016

Ramalho AS, Beck S, Penque D, Gonska T, Seydewitz HH, Mall M, Amaral MD (2003) Transcript analysis of the cystic fibrosis splicing mutation $1525-1 \mathrm{G}>\mathrm{A}$ shows use of multiple alternative splicing sites and suggests a putative role of exonic splicing enhancers. $\mathrm{J}$ Med Genet 40(7):e88
Raponi M, Kralovicova J, Copson E, Divina P, Eccles D, Johnson P, Baralle D, Vorechovsky I (2011) Prediction of single-nucleotide substitutions that result in exon skipping: identification of a splicing silencer in BRCA1 exon 6. Hum Mutat 32:436-444

Reese MG, Eeckman FH, Kulp D, Haussler D (1997) Improved splice site detection in genie. J Comp Biol 4(3):311-323

Rogozin IB, Milanesi L (1997) Analysis of donor splice sites in different eukaryotic organisms. J Mol Evol 45(1):50-59

Sanz DJ, Hollywood JA, Scallan MF, Harrison PT (2017) Cas9/gRNA targeted excision of cystic fibrosis-causing deep-intronic splicing mutations restores normal splicing of CFTR mRNA. PLoS One 12(9):e0184009

Schwartz S, Hall E, Ast G (2009) SROOGLE: webserver for integrative, user-friendly visualization of splicing signals. Nucleic Acids Res 37(Web Server issue):W189-W192

Shapiro MB, Senapathy P (1987) RNA splice junctions of different classes of eukaryotes: sequence statistics and functional implications in gene expression. Nucleic Acids Res 15(17):7155-7174

Sharma N, Sosnay PR, Ramalho AS et al (2014) Experimental assessment of splicing variants using expression minigenes and comparison with in silico predictions. Hum Mutat 35(10):1249-1259

Shibata A, Okuno T, Rahman MA, Azuma Y, Takeda J, Masuda A, Selcen D, Engel AG, Ohno K (2016) IntSplice: prediction of the splicing consequences of intronic single-nucleotide variations in the human genome. J Hum Genet 61(7):633-640

Singh G, Cooper TA (2006) Minigene reporter for identification and analysis of cis elements and trans factors affecting pre-mRNA splicing. BioTechniques 41(2):177-181

Siva K, Covello G, Denti MA (2014) Exon-skipping antisense oligonucleotides to correct missplicing in neurogenetic diseases. Nucleic Acid Ther 24(1):69-86

Slaugenhaupt SA, Blumenfeld A, Gill SP, Leyne M, Mull J, Cuajungco MP, Liebert CB, Chadwick B, Idelson M, Reznik L, Robbins C, Makalowska I, Brownstein M, Krappmann D, Scheidereit C, Maayan C, Axelrod FB, Gusella JF (2001) Tissue-specific expression of a splicing mutation in the IKBKAP gene causes familial dysautonomia. Am J Hum Genet 68:598-605

Smith PJ, Zhang C, Wang J, Chew SL, Zhang MQ, Krainer AR (2006) An increased specificity score matrix for the prediction of SF2/ASFspecific exonic splicing enhancers. Hum Mol Genet 15(16):2490 2508

Sobczyńska-Tomaszewska A, Ołtarzewski M, Czerska K, WertheimTysarowska K, Sands D, Walkowiak J, Bal J, Mazurczak T, NBS CF working group (2013) Newborn screening for cystic fibrosis: Polish 4 years' experience with CFTR sequencing strategy. Eur J Hum Genet 21(4):391-396

Sterne-Weiler T, Sanford JR (2014) Exon identity crisis: disease-causing mutations that disrupt the splicing code. Genome Biol 15(1):201

Svaasand EK, Engebretsen LF, Ludvigsen T, Brechan W, Sjursen W (2015) A novel deep intronic mutation introducing a cryptic exon causing neurofibromatosis type 1 in a family with highly variable phenotypes: a case study. Hereditary Genet 4:152

Symoens S, Malfait F, Vlummens P, Hermanns-Lê T, Syx D, De Paepe A (2011) A novel splice variant in the N-propeptide of COL5A1 causes an EDS phenotype with severe kyphoscoliosis and eye involvement. PLoS One 6(5):e20121

Takahara K, Schwarze U, Imamura Y, Hoffman GG, Toriello H et al (2002) Order of intron removal influences multiple splice outcomes, including a two-exon skip, in a COL5A1 acceptor-site mutation that results in abnormal pro-alpha1(V) N-propeptides and Ehlers-Danlos syndrome type I. Am J Hum Genet 71:451-465

Tazi J, Bakkour N, Stamm S (2009) Alternative splicing and disease. Biochim Biophys Acta 1792(1):14-26

Théry JC, Krieger S, Gaildrat P et al (2011) Contribution of bioinformatics predictions and functional splicing assays to the interpretation of 
unclassified variants of the BRCA genes. Eur J Hum Genet 19(10): $1052-1058$

Turunen JJ, Niemelä EH, Verma B, Frilander MJ (2013) The significant other: splicing by the minor spliceosome. Wiley Interdisc Rev RNA 4(1):61-76

Van de Water NS, Tan T, May S, Browett PJ, Harper P (2004) Factor IX polypyrimidine tract mutation analysis using $\mathrm{mRNA}$ from peripheral blood leukocytes. J Thromb Haemost 2:2073-2075

Vaz-Drago R, Custódio N, Carmo-Fonseca M (2017) Deep intronic mutations and human disease. Hum Genet 136(9):1093-1111

Veltrop M, Aartsma-Rus A (2014) Antisense-mediated exon skipping: taking advantage of a trick from mother nature to treat rare genetic diseases. Exp Cell Res 325(1):50-55

Wagner EJ, Garcia-Blanco MA (2001) Polypyrimidine tract binding protein antagonizes exon definition. Mol Cell Biol 21(10):3281-3288

Wang J, Chang YF, Hamilton JI, Wilkinson MF (2002) Nonsenseassociated altered splicing: a frame-dependent response distinct from nonsense-mediated decay. Mol Cell 10(4):951-957

Wang Z, Rolish ME, Yeo G, Tung V, Mawson M, Burge CB (2004) Systematic identification and analysis of exonic splicing silencers. Cell 119:831-845

Ward AJ, Cooper TA (2010) The pathobiology of splicing. J Pathol 220(2):152-163

Wimmer K, Roca X, Beiglböck H, Callens T, Etzler J, Rao AR, Krainer AR, Fonatsch C, Messiaen L (2007) Extensive in silico analysis of NF1 splicing defects uncovers determinants for splicing outcome upon 5' splice-site disruption. Hum Mutat 28(6):599-612
Xiong F, Gao J, Li J et al (2009) Noncanonical and canonical splice sites: a novel mutation at the rare noncanonical splice-donor cut site (IVS4+1 A $>\mathrm{G}$ ) of SEDL causes variable splicing isoforms in $\mathrm{X}$ linked spondyloepiphyseal dysplasia tarda. Eur J Hum Genet 17(4):510-516

Xiong HY, Alipanahi B, Lee LJ et al (2015) The human splicing code reveals new insights into the genetic determinants of disease. Science (New York, NY) 347(6218):1254806

Xu W, Yang X, Hu X, Li S (2014) Fifty-four novel mutations in the NF1 gene and integrated analyses of the mutations that modulate splicing. Int J Mol Med 34(1):53-60

Yeo G, Burge CB (2004) Maximum entropy modeling of short sequence motifs with applications to RNA splicing signals. J Comput Biol 11(2-3):377-394

Zeng L, Liu W, Feng W et al (2013) A novel donor splice-site mutation of major intrinsic protein gene associated with congenital cataract in a Chinese family. Mol Vis 19:2244-2249

Zhang XH, Chasin LA (2004) Computational definition of sequence motifs governing constitutive exon splicing. Genes Dev 18(11): $1241-1250$

Zhang C, Li WH, Krainer AR, Zhang MQ (2008a) RNA landscape of evolution for optimal exon and intron discrimination. Proc Natl Acad Sci U S A 105:5797-5802

Zhang Z, Lotti F, Dittmar K et al (2008b) SMN deficiency causes tissuespecific perturbations in the repertoire of snRNAs and widespread defects in splicing. Cell 133(4):585-600

Zuker M (2003) Mfold web server for nucleic acid folding and hybridization prediction. Nucleic Acids Res 31(13):3406-3415 